\title{
Pituitary hyperplasia: a complication of the pseudomalabsorption of thyroxine
}

This article was published in the following Dove Press journal:

International Journal of General Medicine

26 April 2013

Number of times this article has been viewed

\author{
Mary-Anne Doyle \\ Heather A Lochnan \\ Division of Endocrinology, University \\ of Ottawa, Ottawa, ON, Canada
}

Objective: "The pseudomalabsorption of thyroxine" has been used to describe patients with hypothyroidism who fail to comply with their treatment. We describe a unique case of a 32-yearold with hypothyroidism who developed pituitary hyperplasia and hyperprolactinemia secondary to the pseudomalabsorption of thyroxine.

Investigations and treatment: After baseline thyroid-function tests were performed, the patient was administered levothyroxine $0.5 \mathrm{mg}$ under the supervision of a registered nurse. Thyroid function testing was repeated at 30,60, 120, and 180 minutes. Arrangements were made for further daily supervised loading of levothyroxine $0.1 \mathrm{mg}$.

Results: With the administration of $0.5 \mathrm{mg}$ levothyroxine, free thyroxine levels increased by 120 minutes, and with daily supervised dosing of $0.1 \mathrm{mg}$ there was normalization of the thyroid hormone levels and a reduction of thyroid-stimulating hormone levels. Maintenance of thyroid-stimulating hormone $<15 \mathrm{mU} / \mathrm{L}$ for 2 weeks led to a reduction in prolactin levels and regression in the size of the pituitary on magnetic resonance imaging.

Conclusion: If left untreated, these patients face significant morbidity and are at risk of developing pituitary hyperplasia, complications from an increase in pituitary size, hyperprolactinemia, and potentially myxedema coma. Recognizing pituitary hyperplasia and hyperprolactinemia as a complication from the pseudomalabsorption of levothyroxine may prevent the potential of a misdiagnosis of a prolactinoma leading to unnecessary investigations and inappropriate treatment. Patient awareness of this serious complication and the rapid, demonstrable resolution with adequate thyroid hormone replacement may provide motivation to comply with supervised dosing of levothyroxine. It has also been suggested that supervised treatment enables the individual to maintain their patient status, which may be in part the motivation behind this disorder.

Keywords: hypothyroidism, pituitary hyperplasia, hyperprolactinemia, pseudomalabsorption

\section{Introduction}

Primary hypothyroidism is a common medical condition, and may be a significant cause of morbidity if left untreated. The symptoms of hypothyroidism, including weight gain, constipation, fatigue, cold intolerance, hair loss, and poor concentration, can be debilitating. Typically, the symptoms associated with this disorder are effectively treated with an oral replacement of thyroxine at an average daily dose of $1.6 \mathrm{mcg} / \mathrm{kg}$ ideal body weight. ${ }^{1}$ The correct dosing is usually confirmed with the resolution of symptoms and normalization of thyroid-stimulating hormone (TSH) levels within 6-8 weeks.

One would expect that the debilitating nature of this disorder and the improvement with treatment would be reason enough for patients to comply with therapy. However, there
Correspondence: Mary-Anne Doyle Ottawa Hospital, 1967 Riverside Drive 4th floor, Ottawa, ON KIH 7W9, Canada

$\mathrm{Tel}+\mathrm{I} 6137388400$

Fax + I 6137388327

Email madoyle@ottawahospital.on.ca 
have been a number of cases described where patients intentionally fail to take their prescribed thyroid medication..$^{2-7}$ These patients are believed to suffer from an underlying psychiatric disorder; more specifically, they are believed to suffer from factitious disorder, or as it has been termed by the authors in these cases, "pseudomalabsorption of thyroxine."

We describe a case report of a patient with a persistently elevated TSH level despite high doses of oral thyroxine who subsequently developed an enlarged pituitary and hyperprolactinemia. These clinical findings are believed to be the result of pseudomalabsorption of thyroxine.

This article will highlight the factors that may interfere with thyroxine treatment, the consequences of untreated hypothyroidism and management of patients with pseudomalabsorption of levothyroxine.

\section{Case report Background}

A 32-year-old woman presented with a 2-year history of elevated TSH levels $(>100 \mathrm{mU} / \mathrm{L}$, normal range $0.32-5.00 \mathrm{mU} / \mathrm{L}$ ) and undetectable free thyroxine/ triiodothyronine $\left(\mathrm{FT}_{4} / \mathrm{FT}_{3}\right)$ levels despite increasing doses of oral thyroxine. At the time of presentation, she had been prescribed a thyroxine dose of $0.5 \mathrm{mg}$ /day and liothyronine $0.125 \mathrm{mg}$ daily. She had been on these doses for more than 6 months. On presentation, the patient complained of vague symptoms of weakness, but clinically there was no evidence of profound hypothyroidism. The patient was subsequently found to have an elevated prolactin level and enlarged pituitary on magnetic resonance imaging.

\section{Investigations and laboratory findings}

Table 1 provides details of the investigations and results that were carried out to rule out various factors that may have interfered with the absorption and clearance of thyroxine in this patient.

\section{Treatment}

With no evidence of malabsorption and absence of another medical condition to explain the lack of response to the high doses of levothyroxine, arrangements were made for supervised treatment with $0.5 \mathrm{mg}$ of thyroxine treatment initially and then daily loading with $0.1 \mathrm{mg}$ of levothyroxine and liothyronine $25 \mathrm{mcg}$ for 5 days (Table 2).

\section{Results}

Within 5 days of treatment, the patient's thyroid hormone levels normalized and TSH levels decreased to $7 \mathrm{mU} / \mathrm{L}$. With TSH levels maintained at $<15 \mathrm{mU} / \mathrm{L}$ for 2 weeks, there was a
Table I Laboratory investigations and test results in a patient with a 2-year history of elevated TSH levels despite increasing doses of thyroxine

\begin{tabular}{|c|c|c|}
\hline Test & Result & Normal range \\
\hline$\overline{\mathrm{TSH}}$ & $712 \mathrm{mU} / \mathrm{L}$ & $0.32-5.00 \mathrm{mU} / \mathrm{L}$ \\
\hline Free $\mathrm{T}_{4}$ & $<5.1 \mathrm{pmol} / \mathrm{L}$ & 9.0-24.0 pmol/L \\
\hline Free $\mathrm{T}_{3}$ & $<\mathrm{I} .7 \mathrm{pmol} / \mathrm{L}$ & $2.5-5.3 \mathrm{pmol} / \mathrm{L}$ \\
\hline $\begin{array}{l}\text { Antithyroid peroxidase } \\
\text { antibodies }\end{array}$ & $\mathrm{I}: 100$ & \\
\hline Prolactin & $137 \mu \mathrm{g} / \mathrm{L}$ & $\mathrm{I}-24 \mu g / \mathrm{L}$ \\
\hline \multirow[t]{4}{*}{$\mathrm{LH}$} & $<1$ & Mid-follicular 2-II IU/L \\
\hline & & Mid-cycle 19-103 IU/L \\
\hline & & Mid-luteal I-I3 IU/L \\
\hline & & Postmenopausal I I-59 IU/L \\
\hline Glucose & $4.4 \mathrm{mmol} / \mathrm{L}$ & $3.8-6.0 \mathrm{mmol} / \mathrm{L}$ \\
\hline Albumin & $44 \mathrm{~g} / \mathrm{L}$ & $35-48 \mathrm{~g} / \mathrm{L}$ \\
\hline Total cholesterol & $8.4 \mathrm{mmol} / \mathrm{L}$ & $3.5-5.2 \mathrm{mmol} / \mathrm{L}$ \\
\hline LDL-c & $6.5 \mathrm{mmol} / \mathrm{L}$ & $<2.50 \mathrm{mmol} / \mathrm{L}$ \\
\hline Triglycerides & $1.53 \mathrm{mmol} / \mathrm{L}$ & $<1.70 \mathrm{mmol} / \mathrm{L}$ \\
\hline HDL-c & $1.2 \mathrm{mmol} / \mathrm{L}$ & $>0.90 \mathrm{mmol} / \mathrm{L}$ \\
\hline CK & II $66 \mu \mathrm{mol} / \mathrm{L}$ & $20-160 \mu \mathrm{mol} / \mathrm{L}$ \\
\hline ALT & $94 \mathrm{U} / \mathrm{L}$ & $9-52 \mathrm{U} / \mathrm{L}$ \\
\hline AST & $95 \mathrm{U} / \mathrm{L}$ & $14-36 \mathrm{U} / \mathrm{L}$ \\
\hline Cortisol & $297 \mu \mathrm{mol} / \mathrm{L}$ & $|7|-536 \mathrm{mmol} / \mathrm{L}$ \\
\hline $\mathrm{Hb}$ & $\mathrm{II} \mathrm{g} / \mathrm{L}$ & $115-155 \mathrm{~g} / \mathrm{L}$ \\
\hline Small-bowel biopsy & Normal & \\
\hline Endoscopy & Normal & \\
\hline
\end{tabular}

Abbreviations: ALT, alanine transaminase; AST, aspartate aminotransaminase; CK, creatine kinase; Hb, hemoglobin; HDL-c, high-density lipoprotein cholesterol; $\mathrm{TSH}$, thyroid stimulating hormone; T4, thyroxine; T3, triiodothyronine; LDL-c, lowdensity lipoprotein cholesterol; LH, luteinizing hormone.

reduction in the prolactin level and normalization of the pituitary on magnetic resonance imaging (Table 2, Figure 1).

\section{Discussion}

Although poor compliance with medication is the most common cause for treatment failure in patients with hypothyroidism, ${ }^{8}$ there are a number of pharmacological agents and disease processes that are known to affect the absorption or metabolism of levothyroxine (Table 3).

\section{Changes in the absorption of thyroxine}

A number of studies have shown that both iron and calcium supplements can potentially decrease the absorption of thyroxine through the formation of a nonabsorbable complex in the gut. ${ }^{9,10}$ Given the increased incidence of hypothyroidism in the elderly population and the association of both osteoporosis and anemia with this condition, it is important to consider the interaction of these supplements with thyroxine as a potential cause for treatment failure. To eliminate this interaction and to maximize the benefit of each treatment, patients are typically advised to separate their medication doses by $2-4$ hours. 
Table $2 \mathrm{TSH}, \mathrm{FT}_{4}$ and $\mathrm{FT}_{3}$ responses after administration of $0.5 \mathrm{mg}$ of levothyroxine orally under the supervision of a registered nurse in the endocrine testing laboratory and supervised daily administration of $0.1 \mathrm{mg}$ levothyroxine $\left(\mathrm{T}_{4}\right)$ daily and $25 \mathrm{mcg}$ liothyronine $\left(\mathrm{T}_{3}\right)$

\begin{tabular}{|c|c|c|c|c|c|c|}
\hline Test/time & 0 minutes & 30 minutes & 60 minutes & 120 minutes & 180 minutes & 24 hours \\
\hline TSH (mU/L) & 712 & $>100$ & $>100$ & 733 & $>100$ & 558 \\
\hline Free $\mathrm{T}_{4}$ (pmol/L) & $<5.1$ & $<5.1$ & $<5.1$ & 6.4 & 6.3 & $<5.1$ \\
\hline Free $T_{3}(\mathrm{pmol} / \mathrm{L})$ & $<1.7$ & $<1.7$ & $<1.7$ & 1.7 & 1.8 & $>1.7$ \\
\hline Test/day & 0 & I & 2 & 3 & 4 & 5 \\
\hline TSH (mU/L) & 500 & 33.4 & 15.6 & 12.58 & 8.96 & 7.19 \\
\hline Free $T_{4}(\mathrm{pmol} / \mathrm{L})$ & $<0.5$ & 8 & 10 & 12 & 13 & 9 \\
\hline Free $T_{3}(p m o l / L)$ & $<1.7$ & 6.6 & 10.8 & 10.3 & 9.9 & 8.7 \\
\hline
\end{tabular}

Abbreviations: $\mathrm{F}$, free; TSH, thyroid stimulating hormone; T4, thyroxine; T3, triiodothyronine.

Other studies have shown that gastrointestinal disorders and anatomical gastrointestinal abnormalities, such as untreated celiac disease and short-gut syndrome, may affect the absorption of thyroxine. ${ }^{11,12}$ Celiac disease is an important consideration in this group of patients, considering the autoimmune association between these two disorders and the frequency in which they occur in patients simultaneously. In terms of patients with celiac disease, normalization of thyroid hormone levels and TSH have been observed once a gluten-free diet has been implemented. ${ }^{11}$

Normal absorption of thyroxine is also known to be affected by changes in the acidic environment of the stomach. Specifically, it has been shown that patients with impaired gastric acid secretion, whether secondary to Helicobacter

Table 3 Medical conditions and pharmacological agents that should be considered when TSH levels fail to normalize in patients who are treated with oral thyroxine for hypothyroidism

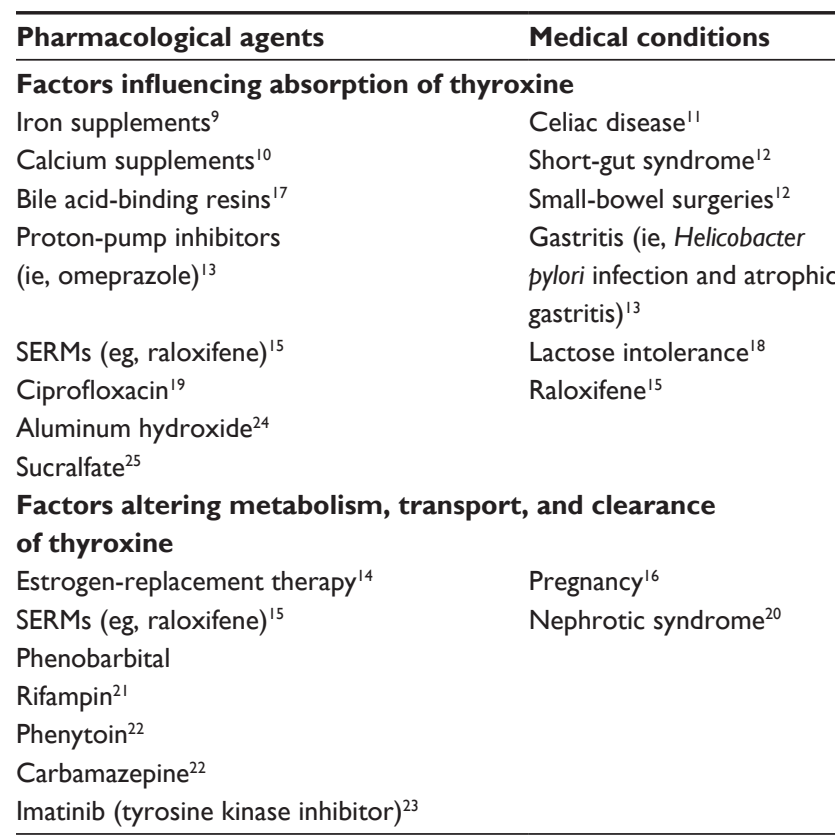

Abbreviations: SERM, selective estrogen receptor modulator; TSH, thyroid stimulating hormone. pylori infection or atrophic gastritis, required higher doses of thyroxine-replacement therapy to become euthyroid. ${ }^{13}$ Similar but reversible findings were also seen in patients treated with omeprazole, a proton-pump inhibitor used to suppress acid secretion. ${ }^{13}$

\section{Changes in the metabolism, clearance, and transport of thyroxine}

Other common medications to consider in this group of patients are estrogen-replacement therapy and the selective estrogen receptor modulator raloxifene. Arafah showed that a group of 18 postmenopausal women treated with thyroxinereplacement therapy demonstrated increases in serum thyroxine and thyroxine-binding globulin (TBG) concentrations while receiving estrogen treatment. ${ }^{14}$ However, patients with a diagnosis of hypothyroidism had decreased $\mathrm{FT}_{4}$ levels ( $22 \pm 5 \mathrm{pmol} / \mathrm{L}$ to $18 \pm 4 \mathrm{pmol} / \mathrm{L})$ and increased serum thyrotropin levels $(0.9 \pm 1.1$ to $3.2 \pm 3.1)$. The coadministration of raloxifene and levothyroxine has also resulted in increased dosing requirements for thyroxine. ${ }^{15}$ It is not clear whether the increased dosing of thyroid-replacement treatment is related to an absorption problem or related to a change in the TBG level. Garwood et al report a case where separation of these medications by 12 hours enabled their patient to reduce her
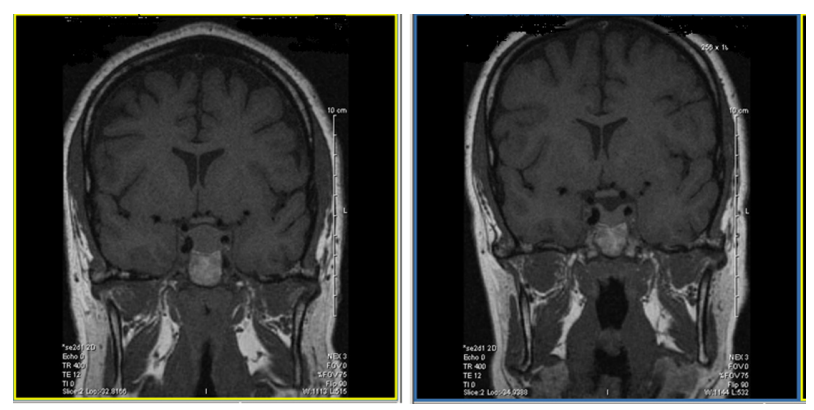

Figure I Magnetic resonance images depicting marked pituitary hyperplasia while thyroid-stimulating hormone levels were $>100 \mathrm{mU} / \mathrm{L}$ (left); thyroid-stimulating hormone levels were maintained $<15 \mathrm{mU} / \mathrm{L}$ for 2 weeks (right). 
thyroxine dosage, suggesting that it may be related to absorption, although the mechanism is unclear. ${ }^{15}$

In younger female patients, pregnancy should also be considered as a potential cause for increasing TSH levels and the need for an increase in thyroxine dosing, particularly in previously stable patients. Similar to patients on estrogenreplacement therapy, the increased thyroid replacement dosing is attributed to an increase in TBG, resulting in decreased levels of $\mathrm{FT}_{4}$ and $\mathrm{FT}_{3}$ and subsequent rises in TSH levels. ${ }^{16}$ The increased thyroxine dosage requirements have been estimated at approximately $45 \%$ higher than their regular dose of thyroxine. ${ }^{16}$

Once each of the various factors discussed above has been thoroughly investigated and eliminated, pseudomalabsorption of thyroxine should be considered in patients failing to achieve normal TSH despite high levels of thyroxine. This diagnosis and normal intestinal absorption can be confirmed through a supervised loading doses of up to $1 \mathrm{mg}$ of oral thyroxine. ${ }^{5}$ It is often recommended that this be completed when patients are fasting, as uptake of thyroxine has been found to be greater in a fasting state. ${ }^{2}$ Patients in these situations should respond with a rapid lowering of their TSH levels and an increase in $\mathrm{FT}_{4}$ levels. It has been reported that most levothyroxine absorption takes place within the first few hours of administration and that serum $\mathrm{FT}_{4}$ levels peak within 2 hours of administration. ${ }^{26}$

Patients such as the one described in this case report are often emphatic about their compliance with the prescribed treatment. This typically makes treatment of their underlying thyroid disorder difficult.

The obvious consequence of untreated hypothyroidism is the persistence of the common symptoms of fatigue, weight gain, constipation, and poor concentration, and the morbidity associated with each of these. However, there are more serious and potentially life-threatening consequences of hypothyroidism if left untreated. Specifically, myxedema coma is a rare but serious medical emergency and definitely the most severe complication of decompensated hypothyroidism. It is often the result of coexisting medical conditions or drugs, and has been found to have a mortality rate of approximately $80 \%$ in untreated patients. ${ }^{1}$

Another rare and potentially severe complication of untreated hypothyroidism is the development of a pituitary hyperplasia and hyperprolactinemia, as was seen in our patient. Although there have been no documented cases where specifically the intentional noncompliance with thyroxine treatment has led to the development of pituitary hyperplasia, it is well established that one of the potential causes for hyper- prolactinemia and pituitary hyperplasia is hypothyroidism. ${ }^{26,27}$ In these situations, the increase in pituitary size and elevated prolactin secretion are felt to be secondary to increased synthesis of thyroid releasing hormone (TRH) in response to chronically low thyroid hormone levels. The development of pituitary hyperplasia in itself has the potential for quite severe complications, including headaches, neurological deficits, and visual loss. Prolonged hyperprolactinemia may lead to infertility, hypopituitarism, and low bone density. ${ }^{28}$

Although hypothyroidism is clearly not the only cause of a pituitary hyperplasia and elevated prolactin levels, resolution of these findings with appropriate treatment of the hypothyroidism suggests that this is the most likely explanation in the case presented here.

Success has been reported with weekly observational administration of thyroxine. ${ }^{3}$ Specifically, Grebe et al demonstrated through their study that once-weekly dosing was an effective means of maintaining TSH levels and thyroid hormone levels within relatively normal ranges, and did not appear to place the patient at risk of toxic complications associated with high doses of thyroxine. ${ }^{28}$ Kubota et al explain that with this type of arrangement, the patient maintains their status as a "patient," the hypothyroid condition is treated, and the risks of serious complications are avoided. ${ }^{3}$

\section{Conclusion}

This case highlights the serious complication of pituitary hyperplasia that may occur with prolonged and untreated hypothyroidism in the context of pseudomalabsorption of levothyroxine. Recognizing pituitary hyperplasia and hyperprolactinemia as a potential complication of this disorder may also prevent the potential misdiagnosis of a prolactinoma leading to unnecessary investigations and inappropriate treatment. Supervised loading of levothyroxine can help to confirm this disorder and avoid extensive and unnecessary investigations. Also unique to this case report was the rapid resolution of this pituitary abnormality with supervised dosing of levothyroxine. Patient awareness of this serious complication and the rapid, demonstrable resolution with adequate thyroid hormone replacement may provide the motivation to comply with levothyroxine treatment.

\section{Disclosure}

The authors report no conflicts of interest in this work.

\section{References}

1. Mandel S, Brent G, Larsen PR. Levothyroxine therapy in patients with thyroid disease. Ann Intern Med. 1993;119:492-502. 
2. Ain KB, Refetoff S, Fein HG, Weitraub BD. Pseudomalabsorption of levothyroxine. JAMA. 1991;266:2118-2120.

3. Kubota S, Matsuzuka F, Kuma K, Miyauchi A. Successful management of a patient with pseudomalabsorption of levothyroxine. Int J Psychiatry Med. 2003;33:183-188.

4. Lips DJ, van Riesen MT, Voigt V, Venekamp W. Diagnosis and treatment of levothyroxine pseudomalabsorption. Neth J Med. 2004;62: 114-118.

5. Ogawa D, Otsuka F, Mimura U, et al. Pseudomalabsorption of levothyroxine: a case report. Endocr J. 2000;47:45-50.

6. Payer J, Sladekova K, Kinova S, et al. Autoimmune thyroiditis with severe hypothyroidism resistant to the treatment with high perioral doses of thyroxine: case report. Endocr Regul. 2000;34:189-193.

7. Srinivas V, Oyibo S. Levothyroxine pseudomalabsorption and thyroxine absorption testing using high-dose levothyroxine: a case report and discussion. Endocr Pract. 2010;16:1012-1015.

8. Hanna FWF, Lazarus JH, Scanlon MF. Fortnightly review: controversial aspects of thyroid disease. BMJ. 1999;319:894-899.

9. Campbell NR, Hasinoff BB, Stalts H, Rao B, Wong NC. Ferrous sulfate reduces thyroxine efficacy in patients with hypothyroidism. Ann Intern Med. 1992;117:1010-1013.

10. Csako G, McGriff N, Rotman-Pikielny P, Sarlis N, Pucino F. Exaggerated levothyroxine malabsorption due to calcium carbonate supplementation in gastrointestinal disorders. Ann Pharmacother. 2001;35:1578-1582.

11. Jiskra J, Limanova Z, Vanickova Z, Kocna P. IgA and IgG antigliadin, IgA anti-tissue transglutaminase and antiendomysial antibodies in patients with autoimmune thyroid diseases and their relationship to thyroidal replacement therapy. Physiol Res. 2003;52:79-88.

12. Stone E, Leiter LA, Lambert J, Silverberg J, Jeejeebhoy K, Burrow G. L-thyroxine absorption in patients with short bowel. J Clin Endocrinol Metab. 1984;59:139-141.

13. Centanni M, Gargano L, Cannettieri G, et al. Thyroxine in goiter, Helicobacter pylori infection and chronic gastritis. New Engl J Med. 2006;354:1787-1791.

14. Arafah BM. Increased need for thyroxine in women with hypothyroidism during estrogen therapy. $N$ Engl J Med. 2001;344:1743-1749.
15. Garwood CL, Van Shepen KA, McDonough RP, Sullivan AL. Increased thyroid-stimulating hormone levels associated with concomitant administration of levothyroxine and raloxifene. Pharmacotherapy. 2006;26: $881-885$.

16. Mandel SJ, Larsen PR, Seely EW, Brent GA. Increased need for thyroxine during pregnancy in women with primary hypothyroidism. New Engl J Med. 1990;323:91-96.

17. Harmon S, Seifert C. Levothyroxine-cholestyramine interaction reemphasized. Ann Intern Med. 1991;115:658-659.

18. Munoz-Torres M, Varsvsky M, Alonso G. Lactose intolerance revealed by severe resistance to treatment with levothyroxine. Thyroid. 2006;16: 1171-1173.

19. Cooper JG, Harboe K, Frost SK, Skadberg O. Ciprofloxacin interacts with thyroid replacement therapy. BMJ. 2005;330:1002.

20. Junglee NA, Scanlon MF, Rees DA. Increasing thyroxine requirements in primary hypothyroidism: don't forget the urinalysis! J Postgrad Med. 2006;52:201-203.

21. Nolan SR, Self TH, Norwood JM. Interaction between rifampin and levothyroxine. South Med J. 1999;92:529-531.

22. Surks M, DeFesi C. Normal serum free thyroid hormone concentrations in patients treated with phenytoin or carbamazepine. A paradox resolved. JAMA. 1996;275:1495-1498.

23. De Groot J, Zonnenberg B, Plukker J, van Der Graaf W, Links T. Imantinib induces hypothyroidism in patients receiving levothyroxine. Clin Pharmacol Ther. 2005;78:433-438.

24. Sperber A, Liel Y. Evidence for interference with intestinal absorption of levothyroxine sodium by aluminum hydroxide. Arch Int Med. 1992; 152:183-184.

25. Sherman S, Tielens E, Ladenson R. Sucralate and the absorption of L-thyroxine. Am J Med. 1994;90:531-535.

26. Passeri E, Tufano A, Locatelli M, Lania AG, Ambrosi B, Corbetta S, Large pituitary hyperplasia in severe primary hypothyroidism. J Clin Endocrinology Metab. 2011;96:22-23.

27. Schlechte JA. Prolactinoma. New Engl J Med. 2003;349:2035-2041.

28. Grebe SK, Cooke RR, Ford HC, et al. Treatment of hypothyroidism with once weekly thyroxine. J Clin Endocrinol Metab. 1997;82:870-875.
International Journal of General Medicine

\section{Publish your work in this journal}

The International Journal of General Medicine is an international, peer-reviewed open-access journal that focuses on general and internal medicine, pathogenesis, epidemiology, diagnosis, monitoring and treatment protocols. The journal is characterized by the rapid reporting of reviews, original research and clinical studies across all disease areas.

\section{Dovepress}

A key focus is the elucidation of disease processes and management protocols resulting in improved outcomes for the patient. The manuscript management system is completely online and includes a very quick and fair peer-review system. Visit http://www.dovepress.com/ testimonials.php to read real quotes from published authors. 